\title{
Reflexiones en torno a la extrema violencia que ha acompañado a la crisis social de Chile
}

\author{
Reflections around the extreme violence accompanying the social crisis in Chile
}

Otto Dörr ${ }^{1,2}$

Palabras clave: crisis social; conducta violenta; ética narrativa; personalidad limítrofe; deterioro del lenguaje; postmodernidad

\section{Señor Editor,}

El 18 de octubre de este año 2019 se inició en Chile una severa crisis social, desencadenada por un alza marginal en el precio del Metro, pero que - según los dichos de los mismos manifestantes - era la expresión de un descontento por los "abusos" (no bien definidos), la desigualdad, las bajas pensiones, la mala salud, etc. En forma casi paralela, hemos visto manifestaciones violentas en contra de la autoridad en Ecuador, Bolivia y Colombia. En años anteriores se habían dado fenómenos semejantes en Inglaterra, Francia, España y Grecia, que se han repetido este año en Francia y en España. La crisis chilena ha sido, sin embargo, la más violenta de todas, porque a las marchas y gritos se han agregado incendios y profanaciones de iglesias, saqueos de supermercados y destrucción de monumentos a nuestros héroes.

La primera pregunta que habría que plantearse es si todas estas muestras de descontento y rabia tienen algo en común, a pesar de haber sido desencadenadas por motivos diferentes. Mi respuesta es que sí. Este fenómeno de descontento observado en países de Europa y Latinoamérica obedece a una crisis de identidad provocada por el proceso de globalización. Ésta ha generado una erosión de los valores que alimentan el alma de los diversos pueblos (Dörr-Zegers, 2013). El filósofo francés Paul Ricoeur (1996) sostiene que el fenómeno de la civilización se muestra en tres niveles: el de los útiles, el de las instituciones y el de los valores. Los útiles (todos los objetos tecnológicos y culturales) son universales por definición. Las instituciones ordenan la vida social, y, con algunas diferencias, muestran también una cierta universalidad. Los valores, en cambio, son propios de cada cultura. Ahora, en lo más profundo de este tercer nivel reside la verdadera esencia del fenómeno civilizatorio, el "núcleo ético-mítico". Éste está constituido, en primer lugar, por la narración fundacional de una cultura (la tradición greco-romano-judeo-cristiana y particularmente, la historia de Cristo y los evangelios, en el caso de occidente; la historia de Mahoma y el Corán en el mundo islámico, etc.). De este relato derivan los principios éticos que imperan en una sociedad determinada, pero éste núcleo está formado también por las imágenes y símbolos mediante los cuales cada grupo expresa su comprensión de lo sagrado, de la realidad, de sí mismo y de los otros. En este nivel radicaría la máxima diversidad. Ahora bien, ocurre que la sociedad global de consumo ha dado cabal cumplimiento a la tarea de que los útiles sean de acceso universal y ha sido positiva en cuanto ha permitido mejores condiciones de vida para gran parte de la humanidad, pero ha tenido como trágica consecuencia la erosión del núcleo ético-mítico que de algún modo sostenía a cada grupo, nación o cultura. La filósofa chilena Ana Escríbar (2013) afirma que la gran contradicción de nuestro tiempo es la existente entre la creciente racionalidad de los útiles - cada vez más abundantes y eficaces - y la irracionalidad de poner como único valor compartido por la humanidad entera, el desarrollo económico. Yo agregaría que también la "muerte de Dios" anunciada por Nietzsche (1883), vale decir, la pérdida de vigencia de los valores considerados absolutos y eternos, ha contribuido también a la sensación de desamparo y desorientación que afecta a buena parte de occidente.

Al mismo tiempo se ha venido produciendo una profunda crisis de identidad, particularmente en los jóvenes. A diferencia de lo que ocurrió durante siglos, cuando la identidad de cada cual derivaba de la tradición familiar, de la clase social o del esfuerzo personal (el self-made man de los norteamericanos) - junto a la mayor o menor identificación con el mito fundacional - hoy, al perder vigencia estas fuentes de identidad, los jóvenes empiezan a ser dominados por los medios de comunicación de masas y los objetos de consumo.

(1) Unidad Docente de Postgrado de la Facultad de Medicina de la Universidad de Chile en el Hospital Psiquiátrico. Santiago, Chile.

(2) Centro de Estudios de Fenomenología y Psiquiatría de la Universidad Diego Portales, Santiago, Chile.

Autor de correspondencia: odoerrz@gmail.com 
El carácter cambiante, tanto de estos objetos como de las modas, hace que la identidad sea muy frágil, y que la "difusión de la identidad" - propia de la "personalidad limítrofe", surgida recién en la postmodernidad - se vaya haciendo cada día más frecuente. Contribuye también a esta falta de identidad, así como a otros rasgos de la personalidad limítrofe, como la impulsividad y las autolesiones, la paulatina pérdida de lenguaje que se observa en la juventud en general y en Chile en forma más acentuada. Esto porque la falta de palabras - y por ende de pensamientos - conduce necesariamente a una falla en lo que se llama "mentalización" (Bateman \& Fonagy, 2012). Se entiende por tal la capacidad de poner nombre y diferenciar los respectivos sentimientos y emociones y poder así interpretar mejor tanto el propio comportamiento como el de los otros. Esto llevaría a los jóvenes a vivencias angustiosas y a una gran inestabilidad en el concepto de sí mismos. Es en esta búsqueda de sí mismo que aparecen estas típicas conductas juveniles de la postmodernidad, como los tatuajes, los piercings y en momentos de angustia y vacío extremos, las automutilaciones. La relación de todos estos fenómenos con la falta del lenguaje se puede comprender mejor si se piensa que para Ricoeur (1996) también la identidad personal - no solo la colectiva - es producto de una narración, la de la historia que uno se cuenta y cuenta al otro de su propia vida. Esta referencia al otro en la génesis de la identidad hace que ésta tenga siempre una connotación ética. Yo le cuento mi historia al otro y él me la cuenta a mí, y lo que da unidad a mi persona, a mi identidad, a pesar de los cambios que van ocurriendo a lo largo de la vida, es justamente la promesa: yo soy responsable ante otro, lo que alcanza su máxima epifanía en el rostro. El rostro humano tiene una dignidad propia que nadie ha sabido describir mejor que el filósofo lituano-francés Emmanuel Lévinàs. Para él, el rostro del otro es la trascendencia personalizada, porque a través suyo se me muestra la humanidad entera en su indefensión. Al descubrir yo esa fragilidad en el rostro del ser amado, me siento inclinado a decir: "Heme aquí; yo me hago cargo de ti" (Dörr-Zegers, 2000). No deja de ser llamativo el que el rasgo común a todos estos jóvenes que hoy se manifiestan con esa violencia, sea el ocultarse el rostro con una capucha, lo que necesariamente lleva a la desaparición del momento ético en la relación interpersonal.

La segunda pregunta que habría que responder es por qué esta crisis chilena ha alcanzado niveles de violencia muy superiores a los de otros países. Pienso que cuatro factores han contribuido a ello:

1. La ruptura del vínculo con el núcleo ético-mítico del que hablábamos y que compartimos con el resto de occidente, se ha dado en Chile de forma mucho más exagerada por dos razones: una sistemática ideologización de la educación escolar, en sentido contrario a los valores tradicionales, y un dramático descenso en el número de personas que se identifican con el catolicismo - la religión tradicional - desde un 80 a un $45 \%$ de la población.

2. El quiebre del principio de autoridad que se ha venido instalando paulatinamente en nuestra sociedad y cuya máxima expresión se puede encontrar en las "tomas"y destrucciones de colegios y universidades, sin que haya habido castigo o consecuencia alguna para los responsables.

3. El consumo temprano de drogas, en particular de marihuana, que afecta no sólo a las funciones cognitivas -con un descenso promedio a largo plazo de 10 puntos en el C.I. sino también a la capacidad de discernimiento ético, por el daño que produce esta droga en los lóbulos frontales del cerebro, base biológica de la experiencia ética. Las cifras de consumo de marihuana en nuestros escolares y jóvenes son las más altas del mundo (Dörr-Zegers \& Dörr-Álamos, 2014).

4. El deterioro del lenguaje hablado y escrito (Dörr-Zegers, 2010). Esto, porque el vínculo entre el lenguaje y la ética acompaña a nuestra especie desde su aparición en la escala zoológica y en la experiencia individual se manifiesta como"la voz de la conciencia". Puede ser que ésta vaya señalando a posteriori las faltas cometidas, como pretende la interpretación vulgar de la conciencia moral, o puede que - como sostiene Heidegger (1963) - sea anterior y esté siempre remitiendo al individuo a algo así como una culpabilidad originaria; pero en ambos casos la experiencia ética fundamental es un "ser-llamado hacia el más propio poder-ser" y hacia el respeto por el otro, a través de la palabra.

Nuestra población -y, en particular, nuestra juventud - carece del lenguaje suficiente como para narrar y narrarse su propia historia y alcanzar a través de ello una identidad sólida. Desprendidos de los vínculos con el pasado, sin ideales que los proyecten al futuro y carentes de un lenguaje que les permita reflexionar sobre sus responsabilidades y sobre la eticidad de sus acciones, nuestros jóvenes se buscan inútilmente a sí mismos a través de sucedáneos como los tatuajes, los piercings, el alcohol y las drogas, o de manifestaciones de extrema violencia contra el orden establecido, como ha ocurrido en Chile en estas últimas semanas.

De todo lo anterior se desprende que una verdadera superación de esta severa crisis que sufre el país - en rigor más moral que económica - debe pasar por una profunda reforma en la educación, reforma que debe incluir entre otros los siguientes elementos: limitación en el uso de aparatos tecnológicos para evitar el peligro de la "demencia digital" (Spitzer, 2013); estimular el interés por la 
lectura y por la música (ambas fueron esenciales en la educación de la Grecia clásica y por ende, contribuyeron al desarrollo de esa civilización, sin duda la más notable de la historia) (Jaeger, 1957); terminar con la ideologización y la política en los colegios; restablecer el principio de autoridad y la disciplina; reencantar a los jóvenes con la historia patria y sus héroes y plantear, por último, como ideal a alcanzar - siguiendo el modelo de buena parte de los países europeos - el de una sociedad desarrollada sí, pero basada en valores que se hunden en lo más profundo de nuestra tradición, como es el caso de la solidaridad, la justicia y el respeto por el otro. Le saludamos esperando su buena acogida.

\section{Referencias}

Bateman A \& Fonagy P. (2004). Psychotherapy for borderline personality disorder. Mentalization-based treatment. Oxford University Press. London.

Bateman A \& Fonagy P. (eds) (2012). Handbook of Mentalizing in Mental Health Practice. American Psychiatric Publishing, Inc., Washington.

Dörr-Zegers O. (1990). Acerca de las relaciones entre el lenguaje y la experiencia ética. Revista de Filosofía (Chile) 35-36, 57-75.

Dörr-Zegers O. (1992). El lenguaje degradado. Diario El Mercurio, p. A $2,1^{\circ}$ de Marzo.

Dörr-Zegers O. (2000). Fenomenología de la corporalidad en la depresión delirante. Alcmeon, Revista Argentina de Clínica Neuropsiquiátrica 9, 250-259.
Dörr-Zegers O. (2010). Educación y lenguaje. Diario El Mercurio, p. A 2, 19 de junio.

Dörr-Zegers O. (2013). “El fenómeno del descontento". Diario El Mercurio, p. A 4, 26 de julio.

Dörr-Zegers O \& Dörr-Álamos A. (2014). Drogas, política y salud. Diario El Mercurio, p. A 2, 12 de julio.

Dörr-Zegers O. (2014). Drogas y post modernidad. Diario El Mercurio, p. A 2, 24 de agosto.

Escríbar A (2013). Ética Narrativa: Antecedentes y Posibles Aportes al Juicio Moral. Ediciones Universidad Diego Portales, Santiago.

Heidegger M. (1927). Sery Tiempo. Editorial Universitaria, Santiago (1997), 56, 292-294

Jaeger W. (1957) Paidea o los ideales de la cultura griega. Fondo de Cultura Económica, Ciudad de México.

Nietzsche F. (1883). Así habló Zarathustra. Editorial Alianza, Madrid. Ricoeur .P (1996). Sí mismo como otro. Siglo XXI, Madrid.

Spitzer M (2013). Demencia Digital: el peligro de las nuevas tecnologías. Ediciones B, Barcelona. 